\title{
The Communicative Approaches Revisited and the Relevance of Teaching Grammar
}

\author{
Sawsan Ahmed \\ Taif University, KSA, Canada \\ E-mail: sawsanamin@gmail.com \\ Abdulamir Alamin \\ Taif University, KSA, Canada \\ E-mail: aalamin1@hotmail.com
}

Received: July 30, 2011

Accepted: September 1, 2011

Published: January 1, 2012

doi:10.5539/elt.v5n1p2

URL: http://dx.doi.org/10.5539/elt.v5n1p2

\begin{abstract}
The field of English as a second language has gone through a number of changes in the last decades and has seen extreme adjustments throughout the methods of teaching and curriculum planning. This article finds the relevance of the old methods to the new methods. After providing the background it becomes apparent that almost all the older methods have some relevance to the contemporary classroom and linguists are reaching out and calling on teachers to use the old techniques alongside the new techniques. Emphasis in this article, however, is put on the relevance of introducing grammar to the learner, what to introduce, how and when is discussed in light what we know of the communicative.
\end{abstract}

Keywords: Communicative approaches, Teaching grammar

\section{Introduction}

It has been noted that a great deal of development has been taking place in the field of foreign language teaching. Paradoxically, most of these changes have been taking place in the field of methods and strategies of teaching rather than teaching content. Over the years a great diversity has developed in the methods of teaching as opposed to stability in the principles underlying the choices of the materials prepared for teaching. Syllabus is seen rather to be controlled in terms of grammatical and pedagogical considerations.

\section{Historical Background}

Since it has been accepted that language learning consists of acquiring a mastery of the grammatical system, it is not surprising that language programs have a grammatical basis. There are, however, varieties of ways in which language can be presented to the learner. Wilkins drew the attention to two main approaches, the synthetic and the analytic, in his book "Notional Syllabus".

\subsection{The Synthetic Approaches}

In planning courses based on this approach, language items to be taught are broken down to grammatical structures and lexical items. These grammatical structures are taught to the learner carefully and a step-by-step. Such approaches accentuate what Chomsky calls competence as opposed to performance as we will see later on in the development of the communicative syllabuses. (Canal and Swain 1980, Quoted in Brown, 1987: 199) The synthesis of the elements usually takes place in the final stages of learning. Using such syllabus the teacher may use the grammar-translation method or the audio-lingual approach for teaching.

Over the years, syllabus constructors have learned to reduce the number of items to be learned in a given unit. By doing so the learning task is simplified. As a result the same linguistic content can be spread over more units and over a longer period of time and the method of presentation differ from course to another. Thus, the presentation may be explicit grammatical rules or it may be embedded in a dialogue. The vocabulary content, however, can be chosen according to certain criteria. The criteria for choosing words are formed in relation to their usefulness, frequency, range, availability, familiarity, and coverage.

Syllabus constructors commonly choose vocabulary items that mainly "operate" the basic patterns of the language. 
The term frequency, however, refers to the words that are thought to have an immediate use in the classroom. Range refers to the distribution of lexical items over a number of different types of text; whilst availability refers to the lexical items which may not be frequent, but are available to the speaker when he needs them. Familiarity is commonly measured by means of the speaker's responses rather than by the statistical analysis of texts. The term coverage refers to the lexical items which have a wide range of meaning and which could replace other items in a particular context (Wilkins 1976).

It is equally important also to select and grade the grammatical component of the foreign language course in using a synthetic approach. The criteria that are most often related to grammatical content of teaching are: simplicity, regularity, frequency, and contrastive difficulty.

One accepts the simple language forms should be taught before the more difficult. The term simplicity is referred here also in terms of ease of acquisition. The second criterion is regularity, which means that forms that have a high rate of productivity should be taught before those which have a low rate of productivity. The last two criteria, however suggests that early learners should be presented with material that presents fewer contrastive difficulties. There are also other criteria that the syllabus designers need to take into account. One of these is social and pedagogical use or the probability of occurrence in the classroom and teachability. Language courses based on such criteria can be considered to be grammatically based.

\subsection{The Analytic Approaches}

Wilkins (1976) suggested that in this approach language should not be seen as blocks which the learner has to accumulate. The learner, accordingly, should be exposed to a variety of linguistic structures from the beginning of the learning process. In this the structural considerations are secondary when decisions are being made about the way in which the language will be presented to the learner. This type of syllabus has been adopted mainly as a reaction to the grammatical type.

In the 1960s, linguists drew attention to the problem of selecting and grading structures which have resulted in the grammatical syllabus looking at the language from another point of view. They suggested that the structural syllabus ignored the content in which language is used and suggested a compromise between the structural and the contextual syllabus. He said while a language learner is being taught the mechanics of the new language, s/he can simultaneously be taught how to communicate, and respond to the language while it is being used in a certain situation. Moreover, he can be taught to respond in a natural manner.

\subsubsection{The Situation Syllabus}

The type of syllabus came about as a means of overcoming the shortcoming of both the traditional and the audio-lingual methodology. It is closely related to the topical or thematic syllabus and takes the situational needs of the students as the starting point. Its main concern is language in social context. For example, going to the restaurant or at the post office, or buying a ticket for the cinema.

Wilkins (1976) defined the major principles of the situational approach by saying:

"We should predict the situation in which the learner is likely to need the language and then teach the language that is necessary to perform linguistically in these situations." (Wilkins, 1976, p.16) He went on to say that by predicting the situations in which the learner is likely to need the language, the process of learning will become "a more effective process because it will include only what is relevant to the learner." (Ibid, p.17)

In this type of syllabus, language is presented in the form of a dialogue. Wilkins stated that although language is often described as a general system, it is always used in a social context and it cannot be fully understood without references to the context in which it has been used. He suggested that a grammatical syllabus could be "situationalized" by presenting the grammatical structures in the form of a dialogue.

In this approach the teaching content is introduced to learners in a set of selected topics. Each topic presents a situational setting. For example, asking for something in a shop, at a doctor's clinic, at a bank, and so forth. Then, each is subdivided into subordinate topics to talk about. One of the major objectives of this approach is to increase the number of the situations in which the student can perform actively in a foreign language as well as increasing 'the student's ability to use the four basic skills in the foreign language'.

One of the main criticisms of the situational syllabus is that syllabus designers are confronted with the problem of deciding the nature of the language to be included in a given situation of dialogue. Mackey (1977) criticized this approach by suggesting that undercontextualization produced utterances which were grammatically correct but unidiomatic and therefore they did not fit in a situation in which they were used. On the other hand, he warned that over contextualization tends to produce structures which may be idiomatic but can be considered not suitable when 
used outside the context in which they were learned.

Furthermore, there is always an element of the unexpected in spontaneous speech; for example, people do not always go to the post office to buy stamps. People may go to complain about the non-arrival of a parcel or to make a phone call. The possibilities of making requests, expressing doubt, seeking information, occur in almost every situation. There is no certain situation that people express these notions in. Wilkins summed up the value of this type of syllabus in that it is valuable for the learner who needs to be able to handle language situations that are typical.

\subsubsection{The Notional Syllabus}

When it became clear to syllabus designers that grammatical and situational syllabuses had failed to provide the learner with an adequate communicative capacity, the situation was dealt with by using the context as a basis. It is this background against which the proposal for the notional syllabus can best be studied.

The notional syllabus takes communicative capacity as its starting point. In effect, the major concern is not how the speaker expresses himself or when and where, but rather what $\mathrm{s} /$ he communicates through language. Thus, the syllabus designer can draw up and organize the language in terms of content rather than the form of the language.

Wilkins (1976) believed that this type of syllabus was superior to the grammatical syllabus because it provides the learner with the desired communicative competence, and is also superior to the situational syllabus because it ensures that most grammatical forms are included. Additionally, it covers all the language functions instead of only those that typically occur in a certain situation.

According to Wilkins (1976), language needs can be classified into three main categories. The first category is the 'conceptual', or, the 'semantico-grammatical' which covers the kind of meaning which has also been called the 'ideational; or 'cognitive'. Similarities exist as well as differences between language at this level. He classified this category to include Time, Point of Time, Duration and so on.

The second category is 'models' 'modality' in which the attitude of the speaker is conveyed. He classified this category in terms of Scale of Certainty, Scale of Commitment, and so on. The third category covers the communicative function and indicates the purposes of the speaker's communication. It also refers to the role of a sentence in relation to other utterances that have been produced. This part of the interactive process indicates not what is being reported but what the speaker is doing with the utterance. The third of these categories is the least familiar to syllabus designers. It is also the major concern and the important part of the discussion in Wilkins' 1976 'Notional Syllabuses'. He classified these categories into notions, some of which are: approval, disapproval, suasion, agreement, disagreement, and so on. He also proposed the presentation of concepts and functions in a cyclic manner so that the learners as they advance learn to express notions in meaningfully subtle ways to meet the interpersonal relation needs.

\subsubsection{The Functional Notional Syllabus}

The development of this syllabus can be traced to the council of Europe project. In 1977 a group of linguists were invited by the committee of Out-of School Education in the Council of Cultural Co-operation to investigate whether or not it was feasible to create better and more effective conditions for language learning in adults.

The group developed the Threshold Level which set up the specific details of what the students with minimum requirements will know and be able to do in a given situation (Van Ek, 1975). The situation in which they need the language is first broken into social roles (stranger/stranger), (friend/friend). Next these situations are analyzed into psychological roles (neutrality, equality, sympathy, and antipathy), settings and topics. As for reading and writing in the Threshold level, these are limited to such very functional tasks as being able to read signs, menus, writing for accommodation, filling in forms, and so on.

The communicative process of a language learner at the threshold level is, if anything, specific (seeking factual information, expressing/finding out moral, intellectual and emotional attitudes, socializing and getting things done). The group then studies what was involved in each of the functions in detail and listed the semantics and syntactic features required for each. Next, the notions expressed in oral communications were identified (general, as well as specific or topic related). These formed the basic criteria for deciding the actual linguistic forms which the learner needs to know. Finally, the lexicon for the Threshold Level was established. This consists of about a thousand words for production and reception, in addition to another five hundred words included merely for recognition purposes (Van Ek, 1976).

Once the language needs are identified in this precise fashion, units can then be designed to meet these needs and credits assigned for complex of units. Once this unit/credit system has been adopted, it is transferable across boundaries and accordingly it should become clear what the learner presumably knows at a given particular level. 


\section{The Component of a Communicative Syllabus}

The principles on which a syllabus is structured are different from those needed for selecting the linguistic content to be included in it. The former involves a number of extra-linguistic factors that include the educational setting in which the course will be taught, the characteristics of the learner, and the circumstance in which the educational institution operates. However, shortfalls of the past syllabus have also to be made good and teachers must ensure that the learners acquire the ability to communicate in a more appropriate way. This may involve the injection of a large number of components into the new syllabus. In this reshaped syllabus, the components of the communicative syllabus can be listed as follows:

\section{A detailed consideration of the proposals for which the learners wish to acquire the target language.}

2. The clear idea about the setting in which the learners will likely to use the language (physical aspects have to be considered as well as the social).

\section{A clear idea of the social role that the learners will assume in the target language.}

4. The situations in which the learners will participate, i.e. the communicative events in which he or she will be involved: everyday situations, vocational, professional or, academic situations, and so on.

5. The language functions involved in the above mentioned events or what the learner will need to be able to do with or through the target language.

6. The notions involved or what the learner will need to be able to talk about.

7. The skills involved in 'knitting together' of discourse: discourse rhetorical skills.

8. The variety of varieties of the target language that the learners will need and the level of the spoken or written language which he or she will need to teach.

9. The specific grammatical contents that will be needed.

10. The lexical content that will be needed.

The discussion however continued when the immersion experience in Canada and other countries did not deliver the correct grammatical structures necessary for full structural competence in the foreign language. In that experience the emphasis was fully put on the content and form was ignored in an effort to teach it naturally by redirecting the learner's attention away from it. The errors committed by the learners could not be eradicated later. The discussion among linguists continued as language is first and for most a means of communication as Hymes (1972) indicated. He talked about "communicative competence" as opposed to Chomskean "linguistic competence".

\section{Evolving Grammar Instruction}

As the old methods of teaching were discussed it is evident that some of their basic techniques are still indicated today. Researchers have concluded that a balance should be found between communicative and structural methods taking care not to fall heavily on one or the other.

The debate as to the place of grammar instruction within the syllabus dominated the discussion between the linguists and language teachers and syllabus planners throughout much of the past century. Researchers in the 2000s started to look into the merits of the implicit and explicit approaches and reached a consensus that emphasizing communication or form impedes or does not facilitate accurate acquisition of English in adults. Cass and Selinker (2008) insisted after looking at a large body of research, he asserted that complicated forms cannot be acquired by processing meaningful input alone.

Poole (2005) even called for the use of another old technique indicated by another old method which is drilling called for by the Audio-Lingual method in an effort to instill the structure required for correct language use. Norris Ortega (2000) Scott (1990) indicated that experienced teachers realize the merits of grammar correction in the classroom. Many other findings set the linguists and syllabus planners to reconsider introducing the current re-focus-on form stage.

Ellis (2001) described the focus-on-form as "any planned or incidental instructional activity that is intended to induce language learners to pay attention to structures of forms (p. 1-2). He also added that this attention to form should not exclude meaningful communicative contexts. Both grammatical accuracy and communicative abilities can be improved if carefully planned communicative with form focused activities are used. Learners who participated in those activities improved their linguistic accuracy immensely. Ellis (1996) implied that "correctness" is considered paramount as far as advanced speaking and writing proficiency necessary for the achievement of students' academic and vocational aims and goals. That may require an explicit form of instruction. 


\subsection{The Merits of Focus-on-Form Approach}

Empirical studies conducted by Camhi and Ebsworth (2008) have suggested that various focus-on-form techniques have led to more accurate use of language. Instructors, however, should consider the learner's readiness when deciding if the focus-on-form approach is suitable for them in a given context. Lowen (2002) found that small doses of corrective feedback correlated with higher rate of correctness on the behalf of learners instantly as well as in subsequent tests. Introduction of structures should be used with caution, however, since learners at the beginning of their learning stages often struggle to comprehend some of the basic forms of the target language. So, structures should advisably be introduced after the learner has acquired some basic structures and vocabulary and has developed some basic abilities to communicate. Some researchers like Spada and Lightbown (1999) insist that even learners who are not ready to learn form, focus-on-form instruction will help them learn other structures which are associated with the target structure that is presented. Careful planning and implementation are required to strike a balance between meaning and form.

What is the ultimate balance between focus on form and focus on meaning? What has changed since the old "grammar-only-focused approaches" and the new "consciousness-raising to form" approaches? Those questions were best answered by Ellis (2001) when he determined that the instructor should use "those explicit conciseness-raising techniques during which learners are encouraged to be aware of grammar rules from evidence presented in the communicative tasks" (p. 21). Ellis (2008) cautioned syllabus planners that planning a form-intensive syllabus can sometimes demonstrate to learners that the instructor is concerned with form more than with meaning. He also suggests that planning a form-intensive syllabus result in focusing on fewer forms and is time consuming. Incidental or reactive focus allows instructors to target many different linguistic forms as the need arises. Therefore, he suggests the incidental or reactive introduction of form as the best method to deal with learners' "conscious-raising" teaching of form.

\subsection{Internalizing the Target Language System}

There are instances of errors occurring as a result of the learner approximating the knowledge of the target language to his existing knowledge of his mother tongue. Selinker (1972) considers such errors as "a sign of transition towards what he calls the "rule-system" of the target language" (p. 201). Learning happens when the learner internalizes the rules introduced to him/her. Gass (1991) asserted that; for the learner to internalize input they must not only comprehend this input but notice the mismatch between their own system... nothing in the target language is available for intake into the learner's existing system unless it is consciously noticed"(p. 232 ). Schmidt (1990) argued that "subliminal learning is impossible and that intake is what learners consciously notice". (p. 152)

\subsection{Suggested Techniques to Introduce Form}

There are many techniques that have been suggested of when and how to introduce form. Celce-Murcia (2007) suggests that students should be asked to create their own texts with naturally occurring errors and with the teacher referring to those errors; students learn to correct their own errors by realizing them. Such a technique is referred to as awareness-raising or noticing technique. Larson-Freeman (2003) discusses techniques and gives examples of students working together to arrive at the right structural form within a meaningful context.

Another form of noticing is corrective feedback which is introduced by Tomasello and Herron (1988) who carried empirical studies arriving at "the garden path technique" where the learners are lead to overgeneralize, then the induced error are self corrected by the learner. That technique yielded better results that were sustained throughout the course.

\section{Conclusion}

There is a general acceptance for eclectic methods nowadays which include techniques called for by the oldest and the most primitive methods of language teaching, like grammar rule explanation and drilling. What Chomsky theorized many years ago, is still valid today provided that teachers take into consideration what has been theorized after him about communication. All the communicative methods still make sense today provided that form and correctness does not get neglected. Classroom teachers are the ones who have a feel for their students' needs and they are the ones who can decide whether to go one way or the other. Never-the-less a balance is necessary to be found and developing one and ignoring the other will create learners that lack some skills. Relying heavily on form will create learners who are accurate in their production of language but lack knowledge when it comes to cultural and pragmatic use of the language. Whereas, relying heavily on communication will produce learners who produce errors, especially errors-that do not impede communication-that can fossilize and learners with fossilized errors are hardly called successful learners. The contemporary style of teaching including syllabus selection truly calls for an eclectic type of methods and syllabus design. 
Appendix 1 provides a suggested general guideline as to what themes to include to beginners and the grammatical items it covers:

\section{References}

Basturkmen, H., Loewen, S., \& Ellis, R. (2002). Metalanguage in focus on form in the communicative classroom. Language Awareness, 11, 1-13. http://dx.doi.org/10.1080/09658410208667042

Brown, H. D. (2000). Principles of learning and teaching $\left(4^{\text {th }} \mathrm{ed}\right), 775,51$

Camhi, P. J., \& Ebsworth M. E. (2008). Merging a metalinguistics grammar approach with L2 academic process writing: ELLs in community college. TESL-EL, 12. [Online] Available: http://tesl-ej.org/ej46/al.pdf (July 10, 2010)

Cece-Murcia, M. (2007). Towards more context and discourse in grammar instruction. TESL-EL, 11(2). [Online] Available: http://tesl-ej.org/ej46/al.pdf (July 9, 2010)

Ellis, R., (1996). SLA and Language pedagogy. Studies in Second language acquisition, 19, 69-92

Ellis, R., (2008). Principles of instructed second language acquisition. Washington, DC: Centre for Applied Linguistics.

Gass, S., \& Selinker, L. (2008). Second language acquisition: An introductory course. New York: Routledge.

Hymes, D. (1972). “Educational introduction” language and society, 1, 1-14

Larson Freeman, D. (2000). Techniques and practices in language teaching. Oxford University Press.

Mackey, W. F. (1977). The contextual revolt in language training: Its theoretical foundations. Quebec: International centre for research in bilingualism.

Poole, A. (2005). Focus on form instruction: Foundations, applications, and criticism. The Reading Matrix, 5(1), 47-56

Schmidt, R. W. (1994). Implicit learning and cognitive unconscious artificial grammars: London Academic press.

Scott, V. M., (1990). Explicit and implicit grammar teaching strategies: New empirical data. French review, 63, 99-189

Spada, N., \& Lightbown, P. M. (1999). Instruction, first influence, and developmental readiness in second language acquisition. Modern language journal, 83, 1-2. http://dx.doi.org/10.1111/0026-7902.00002

Tomasello, M., \& Herron, C. (1988). Down the garden path: Introducing and correcting Overgeneralization errors in the foreign language classroom. Applied psychologists, 9, 237-240

Trim, J. L. M. (1971). “A European unit-credit system; Modern languages in Scotland”, No.14. The council of Europe.

Van Ek, J. (1975). The threshold level. Strasbourg: Council of Europe.

Wilkins, D. A. Notional syllabus. London: Oxford University Press. 


\section{Appendix 1}

Suggested topics and themes with the grammar rules they include for conscious-raising techniques in the classroom

\begin{tabular}{|ll}
\hline Language functions & Key structures \\
\hline Describing self topics & \\
and others & we/ has... \\
& who has... \\
& I have... \\
& I'm... \\
He/she/it is \\
His/her... is are \\
My... is/are
\end{tabular}

Grammatical items

present simple

has, have

verbs to be "am, is, are".

pronouns

he, she, it

questions with,

"what, who"

Possessive pronouns

"his, her, my"

Numbers "1-12

Counting

Expressing and inquiring

what time is it?

Preposition "at"

about time

what time do you do...?

It's...

I do this at ...

Identifying colours,

Expressing and inquiring about:

it is red

$\mathrm{s} /$ he has

Possessions,

how many ... does s/he have?

Names

Age

what's your name?

Date

location

how old is, are...?

what day is...?

where is ..?

it's in...

it's on...

it's under

it's by

it's near

it's between...

it's behind

Expressing needs

he/she wants

I want

What does s/he want?

present simple

Simple verb statement

Modals "would"

What do you want?

I‘d like

Expressing ability

I can

I can't

Giving orders

do this

Don't do ...

imperatives

negatives sentences

Inquiring about events

what happened?

Present perfect

Talking and inquiring

It has fallen

I'm writing...

who are you writing to?

why do you...?

present continuous

Questions with" who, why" 


\begin{tabular}{|c|c|c|}
\hline Expressing appreciation & $\begin{array}{l}\text { it's lovely } \\
\text { It's terrific }\end{array}$ & \multirow{5}{*}{$\begin{array}{l}\text { present perfect verb "have" } \\
\text { negative and statements in } \\
\text { simple tenses past tenses } \\
\text { and perfect tenses with "had" }\end{array}$} \\
\hline Repeating oneself & I've told you & \\
\hline \multirow[t]{5}{*}{ Narration } & we did... & \\
\hline & We did't... & \\
\hline & It was... & \\
\hline & We had... & \\
\hline & We didn't have & \\
\hline Inquiring about & what's the matter & modal verb "would" \\
\hline State & s/he would not... & \\
\hline Suggestion & let's go & \\
\hline Refusing suggestion & No, thanks & \\
\hline Directing attention & look out & \\
\hline Offering things & have some... & imperatives \\
\hline Inquiring about people & who...with? & Modals with "will" \\
\hline Intentions & I'll be... & \\
\hline \multirow[t]{3}{*}{ Describing states of things } & it's silly & adjectives ending in "ly""ous" \\
\hline & It's deep & \\
\hline & It's lovely & \\
\hline \multirow[t]{2}{*}{ Making requests } & Will you... & \\
\hline & Can I...? & \\
\hline Expressing and inquiring & how heavy is... & questions with "how heavy" \\
\hline \multirow[t]{2}{*}{ About weight and height } & how tall is... & "How high" \\
\hline & I am ... tall & \\
\hline \multirow[t]{2}{*}{ Telling distances } & it's about & "how far" \\
\hline & How far is... & \\
\hline \multirow{2}{*}{ Suggestions } & why not...? & The preposition "about" \\
\hline & $\begin{array}{l}\text { Why don't you...? } \\
\text { where are we going to...? }\end{array}$ & The future \\
\hline Inquiring about time & how are we going to...? & "question techniques" \\
\hline Inquiring about numbers & how many are we ...? & \\
\hline Inquiring about things & what do we need? & \\
\hline Agreeing & I'd love to & \\
\hline
\end{tabular}

